\title{
THE NECESSITY OF A NEW STRATEGY TO FIGHT AGAINST DRUG TRAFFICKING
}

https://doi.org/10.47743/jopafl-2021-20-20

\author{
Ancuța Elena FRANȚ \\ Faculty of Law, „Alexandru Ioan Cuza” University of Iași \\ Iași, Romania, \\ ancuta.frant@uaic.ro
}

\begin{abstract}
The fight against drugs has become a leitmotif of the modern world. However, despite huge financial and human efforts worldwide, the phenomenon of drug trafficking and illicit drug use has not declined significantly. In 2011, the Global Commission on Drug Policy (GCDP) acknowledged that the global fight against drugs had failed. Awareness of this failure led to an analysis of the foundations of the classic anti-drug policy, looking for the reasons that generated the inefficiency of the traditional vision regarding the fight against drugs. It was found that, in essence, traditional anti-drug policies were based on three elements: the eradication of drug production, the annihilation of distribution networks and the prohibition of drug use. In the context of the failure of the traditional conception, another solution is emerging, namely to decrease the demand for drugs. Such a paradigm shift is radical, but necessary, since traditional anti-drug policies have failed and the disastrous consequences of drug trafficking are forcing us to find efficient solutions. The European Union is a pioneer of this new paradigm, as it considers reducing the negative consequences of drug use to be a public health problem and, in the spirit of this idea, provides care for drug users. The real challenge, however, is a massive reduction in drug demand, which would indeed be a long-term solution to the drug problem. It is considered that the best way to reduce the demand for drugs is to raise public awareness of the negative effects of drug use, but effective ways are still being sought to achieve this goal. In parallel with the implementation of this new paradigm, activities specific to traditional anti-drug policy are still needed, in particular those related to the fight against drug trafficking networks.

Keywords: drug trafficking, drug use, reducing drug demand, organised crime, European Union, education.
\end{abstract}

\section{The importance of considering a new approach on fighting against drugs}

The drug issue has been severely affecting modern society for decades. Recent studies point out that the negative consequences of drug consumption are more severe than ever, with approximately 35 million people suffering from drug use disorders worldwide (United Nations, 2019). The negative influence of illicit drug consumption spreads not only to drug consumers, but also on their families, on their communities and on the society as a whole (EU drugs policy, 2021; Latin American Commission on Drugs \& Democracy, 2016). The drug issue affects public safety, public health, environment, labour productivity and endangers security, as it generates crime, violence and corruption (EU drugs policy, 2021). The income obtained by organised crime through illegal drug trade reaches very high figures (at least 30 billion $€$ per year in the European Union), which threatens international financial stability (EU drugs policy, 2021). Also, it is important to emphasize the fact that, often, the money obtained from illegal drug trafficking is used to support other illegal activities, like weapon trade and terrorism (Piazza, 2011). In order to prevent the negative consequences of drug consumption and drug trafficking, the society has been carrying on a true war against those responsible for the drug-related problems. However, 
despite the huge human and financial resources which have been involved in this war, in the present-day we still cannot see significant results (Latin American Commission on Drugs \& Democracy, 2016).

\section{The attitude of some international organisations in refer to adopting a new strategy in fighting drugs}

Given this situation, some organisations had the courage to put forward a bold assertion on the necessity to critically analyse our classic view on drugs and, further, to make a shift on our view referring to drugs. Maybe the most powerful cry for a paradigm shift comes from Latin America, which is, certainly, not at all surprising, because Latin America is one of the regions which has been extremely affected by the violence and corruption associated with drug production, trafficking and consumption. The Latin American Commission on Drugs and Democracy, in 2009, shows that it is time to admit that the so-called 'classic' methods to fight drug-related problems have failed (Latin American Commission on Drugs \& Democracy, 2016). These methods were essentially based on prohibition and included eradication of drug production, dismantling drug trafficking networks and criminalisation of drug consumption (Latin American Commission on Drugs \& Democracy, 2016). A similar view is expressed by the Global Commission on Drug Policy, which, in 2011, asserted that the global war on drugs has failed, with devastating consequences for people and countries worldwide (The Global Commission on Drug Policy, 2011). As regards the United Nations, although it does not expressly admit that the 'traditional war on drugs has failed, clearly shows a change in the approach of the drug problem, for example urging states to allow the use of international controlled drugs for medical and scientific purposes (United Nations Office on Drugs and Crime, 2016). The European Union has also embraced the need for a change in approaching drug fighting. In this respect, it is relevant that The EU Drug Strategy for 2021-2025 includes research, innovation and foresight (EU Drugs Action Plan 2021-2025).

The paradigm shift regarding the methods which should be used in fighting drugs, adopted, as we have seen, by several international structures (in an explicit or implied manner), essentially relies on the following solutions: treating drug consumption as a matter of public health; reducing drug use through education, information and prevention; focusing repression on organised crime (Latin American Commission on Drugs \& Democracy, 2016). It can be seen that reduction of drug demand is considered an important part of the solutions for the drug problem.

\section{Reducing drug demand: an effective solution, which is difficult to obtain}

In theory, the solutions which have been proposed for properly addressing the drug problem seem rational and simple. Although all have a well-defined importance in solving the drug-related issues, it is easy to see that, in order to obtain long-term results, reducing drug demand is, certainly, one of the most appropriate solutions. If there is no demand for drugs, drug production and drug trafficking will diminish and, eventually, vanish. But, in achieving this goal of reducing drug demand, we encounter a serious obstacle. It seems that, previously, programs which have been aimed at reducing drug consumption through education and information did not have the expected results. Some of them were inefficient, 
while others, despite having some effects, are, still, far from reaching the desired effect. The Latin American Commission on Drugs and Democracy actually openly acknowledged that most of the campaigns for preventing drug use which have been implemented all over the world have failed (Latin American Commission on Drugs \& Democracy, 2016). Some studies have reached similar conclusions. A research conducted for the European Monitoring Centre for Drugs and Drug Addiction has found out that universal school-based prevention and universal family-based prevention may be effective in preventing cannabis use, but it could not be drawn a conclusion regarding the effects on using other drugs, due to insufficient data (Sumnall et al., 2017). The same study shows that brief interventions carried out in schools or health institutions with the purpose to prevent drug use are ineffective (Sumnall et al., 2017). Also, results point out that mass-media campaigns (using television, radio, print and the internet) which disseminate information about drugs are ineffective in drug use prevention (Sumnall et al., 2017). It is important to mention that the most widely known drug prevention campaign for teenagers in the United States of America, named Drug Abuse Resistance Education (with the acronym D.A.R.E.) has little or no effect at all. Essentially, in this programme, uniformed police officers go into schools and warn children about the negative effects of drugs. Some studies show that this programme may have even reached the opposite of the desired effect, determining some teenagers to use illegal substances (Lilienfeld \& Arkowitz, 2014). The low or the nonexistent efficiency of this kind of programmes, which are actually based on the principles of the worldwide-spread form of education, urges us to make a deep analysis not only on education referring to drugs, but on our views on education as a whole. It is important to mention that the conclusion that drug-prevention through traditional education does not work is not at all new (Stuart, 1974; Coggans et al., 1991; Tobler, 1986, Brown et al., 1997). Despite relevant information, this conclusion has not been taken into consideration (or at least not enough) by those responsible with implementing drug-prevention programmes.

There are, still, some positive effects which can be achieved in preventing drug use. It seems that results can be obtained if the drug-prevention programmes involve a great amount of interaction between the instructor and the persons in the target - group. Also, it seems that it is important that people are taught the social skills they need in order to refuse drugs and that they have the opportunity to practice these skills with other persons (Lilienfeld \& Arkowitz, 2014; Tobler, 1986). It is, nevertheless, important that some drug prevention programmes have had positive results. However, we highlight the fact that this kind of programmes are difficult to put into practice, because they involve certain amounts of time and cand be performed on small groups of people, as an instructor cannot develop a proper interaction with many people at the same time. Implementing such programmes in educational systems based on traditional methods it is not an easy task and it takes time, while negative effects of the drug problem are growing (United Nations Office on Drugs and Crime, 2020). The information presented above shows that, while being one of the most important long-term solution for the drug problem, reducing drug demand is very hard to achieve. 


\section{Conclusions}

The information presented above clearly proves that we must change our strategy in fighting against drug trafficking. First, we must become aware that, despite decades of trying to repress drug trafficking by using `classic` methods (police force and a severe ban on drug use), there are no significant results. Instead, using these ‘classic ' ways has led to many life losses and to spending huge amounts of money. It is time to honestly approach the drug issue and to see which are the mistakes that have been done and that contributed to the present-day situation. Some may argue that it would be enough to legalize at a large scale the use of the so-called 'recreational drugs`. Indeed, it could be that granting access to 'easy drugs may be a part of the multi-faceted solution, but, for sure, it cannot be its only solution. Adopting such measures should be accompanied by an effective education on the use of such drugs, as `recreational drugs`can still be dangerous. Modern society did not find appropriate solutions for alcohol-related problems, as alcohol is, actually, a drug, which is highly available in most countries. We should think twice before introducing another category of drugs within reach of a large number of people. By saying that, we do not say that the idea of legalizing recreational drugs should be rejected per se; we only want to draw attention that we must be very careful, if we choose to integrate such a solution among those aimed at efficiently addressing drug-related problems.

Of course, in our quest for new strategies in fighting against drugs we must not abandon (at least not yet) the `classic` methods of fighting against drugs. At the same time with changing our paradigm on addressing the drug-related problems, we must still use criminal law enforcement and international criminal cooperation, in order to identify and to punish those involved in drug trafficking. This is absolutely necessary, because drug trafficking and structured groups which organise it pose a very severe threat to the society, and this requires urgent measures. The new paradigm towards drugs, which is still in its infancy, needs time to find efficient ways to obtain tangible results.

The most effective solution, however, seems to be reducing drug demand. Indeed, if people do not wish to take drugs, this, eventually, will lead to the dismantling of organised crime involved in drug trafficking. But such a solution, despite its simplicity, is extremely hard to achieve. Many studies point out that public programmes developed in order to convince people not to use drugs have usually failed. At the same time, research shows that it is possible to teach people how to refrain themselves from becoming drug consumers, but this requires elaborate psychological programmes, which are hard to apply to large groups.

At the end of our study, we point out that a paradigm shift in fighting against drugs is absolutely necessary. At the same time, it is clear that further theoretical and empirical research is needed, in order to find the most effective strategy to fight against drugs in a new manner.

\section{References}

1. United Nations, (2019). World Drug Report 2019. United Nations publication, Sales No. E.19.XI.8.

2. EU drugs policy, (2021). Retrieved from https://www.consilium.europa.eu/en/policies/eu-drugs-policy/. 
3. Latin American Commission on Drugs \& Democracy, (2016). Drugs \& Democracy: Towards a Paradigm Shift. Retrieved from https://www.globalcommissionondrugs.org/wpcontent/uploads/2016/06/drugs-and-democracy_book_EN.pdf .

4. Piazza, J. A., (2011). The illicit drug trade, counternarcotics strategies and terrorism. Public Choice, 149 (3/4): 297-314.

5. The Global Commission on Drug Policy, (2011). War on Drugs: Report of the Global Commission on Drug Policy. Retrieved from http://www.globalcommissionondrugs.org/wpcontent/uploads/2017/10/GCDP_WaronDrugs_EN.pdf .

6. United Nations Office on Drugs and Crime, (2016). Outcome document of the 2016 United Nations General Assembly Special Session on the World Drug Problem (New York, 19-21 April 2016). Our Joint Commitment to Effectively Addressing and Countering the World Drug Problem. Retrieved from https://www.unodc.org/documents/postungass2016/outcome/V1603301-E.pdf .

7. EU Drugs Action Plan 2021-2025. Retrieved from https://www.consilium.europa.eu/media/50592/eudrugs-policy-action-plan.pdf .

8. Sumnall, H. R., Bates, G., and Jones, L., (2017). Evidence review summary: drug demand reduction, treatment and harm reduction (Background paper commissioned by the European Monitoring Centre for Drugs and Drug Addiction for Health and social responses to drug problems: a European guide). Public Health Institute, Liverpool John Moores University, United Kingdom.

9. Lilienfeld, S. O., Arkowitz, H., (2014). Why 'Just Say No` Doesn `t Work. A Popular Program for Preventing Teen Drug Use Does Not Help. Here`s What Does, Retrieved from January $1^{\text {st }}$, 2014, https://www.scientificamerican.com/article/why-just-say-no-doesnt-work/ (Published January $1^{\text {st }}$, 2014).

10. Stuart, R. B., (1974). Teaching facts about drugs: Pushing or preventing. Journal of Educational Psychology, 66(2):189-201. Retrieved from https://doi.org/10.1037/h0036275 .

11. Coggans, N., Shewan, D., Henderson, M., \& Davies, J. B., (1991). The impact of school-based drug education. British Journal of Addiction, 86(9): 1099-1109. Retrieved from https://doi.org/10.1111/j.1360-0443.1991.tb01877.x .

12. Tobler, N. S., (1986). Meta-analysis of 143 adolescent drug prevention programs: Quantitative outcome results of program participants compared to a control or comparison group. Journal of Drug Issues, 16(4), 537-567. Retrieved from https://doi.org/10.1177/002204268601600405 .

13. Brown, J. H., D'Emidio-Caston, M., \& Pollard, J. A., (1997). Students and substances: Social power in drug education. Educational Evaluation and Policy Analysis, 19(1): 65-82. Retrieved from https://doi.org/10.2307/1164520 .

14. United Nations Office on Drugs and Crime, (2020). UNODC World Drug Report 2020: Global drug use rising; while COVID-19 has far reaching impact on global drug markets. Retrieved from https://www.unodc.org/unodc/press/releases/2020/June/media-advisory---global-launch-of-the-2020world-drug-report.html . Creative Commons Attribution - Non Commercial - No Derivatives 4.0 International License. 